\title{
Um sistema para se proteger da escola
}

\author{
Beatris Cristina Possato \\ Universidade Estadual de Campinas
}

\section{Resumo}

Este artigo busca compreender a implementação do "Sistema de Proteção Escolar", uma política pública educacional do Estado de São Paulo, e conhecer seus significados, suas concepções, bem como sua dinâmica e a complexidade desses processos. $\bigcirc$ artigo tece sua análise por meio de entrevistas, tendo seu referencial teórico baseado nos estudos de Michel Foucault para discutir como essa política pública ampara-se na abordagem sistêmica e em uma visão administrativa da educação, utilizando mecanismos do biopoder para agir, ao mesmo tempo, como aparelho disciplinar e aparelho regulamentador estatal, tentando atingir não somente o indivíduo, mas também normalizando um conjunto de escolas como um "sistema". Palavras-chave: Sistema de proteção escolar. Política pública. Biopoder.

\section{A system to protect themselves from the school}

\section{Abstract}

This paper aims at understanding the implementation of the "Protecting School System", an educational public policy of the State of São Paulo and understand their meanings, their conceptions, as well as its dynamics and the complexity of these processes. This study establishes its analysis on interviews, and also on its theoretical perspective based on studies of Michel Foucault. The theoretical perspective that bounds this study instigates a discussion about the referred public policy it is grounded in a systemic approach and administrative vision of education that makes use of biopower mechanisms to step in. At the same time, this policy also works as a disciplinary and state regulatory apparatus that tries not only to reach individuals, but also standardize a number of schools as a "system".

Keywords: School protecting system. Public policy. Biopower. 


\section{Un sistema para protegerse de la escuela}

\section{Resumen}

Este artículo busca entender la implementación del "Sistema de Protección Escolar", una política pública educativa del Estado de São Paulo y saber sus significados, sus concepciones, así como su dinámica y la complejidad de estos procesos. El artículo presenta sus análisis por medio de entrevistas, teniendo su marco teórico basado en los estudios de Michel Foucault para discutir como esta política pública se basa en el enfoque sistémico y en una visión administrativa de la educación, utilizando los mecanismos del biopoder para actuar, al mismo tiempo, como un aparato disciplinar y un aparato regulador estatal, tratando de llegar no sólo al individuo, pero normalizando un conjunto de escuelas como un "sistema".

Palabras-claves: Sistema de protección escolar. Política pública. Biopoder.

\section{Introdução}

Compreendendo que a implementação de uma política pública "é marcada e demarcada pelas influências de todos os atores e das próprias instituições" (MENDES, 2011 , p. 294) e que o estudo desse processo deve analisar, entre outros fatores, o contexto cultural e político, o caráter das decisões, os interesses, os mecanismos institucionais e as preferências dos atores envolvidos (MENDES, 2011 1), é possível considerar que este artigo se arriscará a realizar tal estudo'. Busca-se compreender como se configurou o "Sistema de Proteção Escolar" (SPE), uma política pública educacional do Estado de São Paulo, que veio como resposta às manifestações das violências escolares. Discutem-se aqui as primeiras ações dessa política idealizada pela Secretaria de Estado da Educação de São Paulo (SEESP), junto à Fundação para o Desenvolvimento da Educação (FDE) e a Secretaria da Segurança Pública (SSP). A tentativa, igualmente, é no sentido de compreender os significados dessa política, as concepções defendidas pelos seus representantes, bem como sua dinâmica, sua implementação e a complexidade dos processos, visto que não são estáticos, estão sujeitos a modificações.

Segundo um dos supervisores² responsáveis pela elaboração e implantação dessa política pública, primeiro surgiu a Supervisão de Proteção 
Escolar e Cidadania (SPEC) e o projeto "Sistema de Proteção Escolar" (SPE) que nasceu a partir dessa equipe supervisora. De acordo com o Supervisor, o Sistema de Proteção Escolar atualmente transcende a equipe, "por trazer uma ideia de sistema em relação à ação... a uma ação sistemática" (SUPERVISOR, 2012, p. 18).

A equipe foi criada no final de 2008, início de 2009, impulsionada por duas ocorrências mais específicas nas Escolas Estaduais Amadeu Amaral (CAPRIGLIONE; KAWAGUTI, 2008) e Antônio Firmino de Proença (FREITAS, 2009), em São Paulo. As manifestações de violências nessas escolas foram amplamente divulgadas pela mídia. No entanto, para Supervisor (2012) já existia a percepção do governo da "[...] necessidade de se trabalhar com mais impacto a questão da violência [...]", visto que em uma rede imensa (com mais de 5 mil escolas), apenas existiam ações em departamentos isolados, que atuavam de diferentes maneiras.

Enfim, aconteceram situações que, de fato, tornaram muito claro ao governo que um momento de 'basta' deveria de ser dado e que isso deveria ser tratado de uma maneira sistematizada, de uma maneira centralizada, do âmbito da administração e não mais de uma 'maneira isolada e pontual, como estava sendo tratado antes (SUPERVISOR, 2012, p. 2).

Pouco depois da equipe de supervisão ser criada, houve a troca de gestão da Secretaria da Educação com a saída da socióloga Maria Helena Guimarães de Castro e a entrada do economista Paulo Renato Costa Souza. Nessa mudança, o Secretário Adjunto da Segurança Pública, Guilherme Bueno Camargo, passou a ser Secretário Adjunto da Secretaria de Educação do Estado de São Paulo. Uma nova equipe da Supervisão de Proteção Escolar e Cidadania foi constituída. Com a chegada dos novos Secretários (de Educação e Adjunto) se manteve a Supervisão de Proteção Escolar e Cidadania junto à presidência da Fundação para o Desenvolvimento da Educação e criou-se uma coordenação do Sistema de Proteção Escolar junto ao gabinete da Secretaria da Educação.

Essa transição foi concomitante ao lançamento das ações que já estavam sendo gestadas pela equipe anterior: criar o Sistema Eletrônico de Registro de Ocorrência Escolar (2009), publicar dois manuais (2009) que serão descritos a seguir e, ainda, realizar um contrato de monitoramento nas escolas 
(2009). De acordo com o Supervisor, foi uma transição amigável, gradual, em que as duas equipes conviveram para dar continuidade a algumas ações. Para o Supervisor, havia um caráter inicial mais ligado à segurança pública, que não tinha relação como o perfil das pessoas da equipe antiga, mas que vinha como resposta às manifestações de violência que haviam ocorrido. "É a primeira ideia que aparece num momento de emergência. Foi um pouco o que ocorreu nesses dois episódios dessas escolas. Houve uma determinação do governo: é preciso fazer algo agora. Então começou dessa maneira" (SUPERVISOR, 2012, p.3).

Desse modo, nasce uma das mais representativas políticas públicas atuais no Estado de São Paulo que busca minimizar as violências escolares, gerenciada fortemente pela Secretaria de Segurança Pública e amparada na ideia de sistema.

\section{Um sistema de proteção}

Há um intenso apelo, já destacado no nome "Sistema de Proteção Escolar" e posteriormente identificado no depoimento do supervisor responsá-

156 vel por essa política, à Teoria Geral de Sistemas (TGS) muito utilizada na área administrativa (CHIAVENATO, 2003). Seus fundamentos foram apresentados, em 1937, pelo biólogo alemão Ludwig von Bertalanffy (1975). $\bigcirc$ biólogo buscou inserir, no âmbito das ciências sociais, os conceitos da física, da biologia e da cibernética. Sua intenção seria integrar ciências naturais e sociais. Para Bertalanffy, existem determinados sistemas que poderiam ser analisados em qualquer área de conhecimento, com qualquer especificidade, visto que a finalidade do TGS seria identificar os princípios, as leis e as propriedades que são representativos dos sistemas de modo geral.

sistema, para Von Bertalanffy (1975, p. 84), é um "complexo de elementos em interação". Por meio da teoria geral dos sistemas, seria possível "[...] controlar e investigar a transferência de princípios de um campo para outro, a fim de que não seja mais necessário duplicar ou triplicar a descoberta dos mesmos princípios" (VON BERTALANFFY, 1975, p. 1 15).

$\bigcirc$ funcionalismo de Talcott Parsons (1988) da mesma forma auxiliou na construção desse modelo administrativo de gestão. A teoria de Talcott Parsons (1988) afirma que há uma funcionalidade dos sistemas e que as organizações formais se constituem em um sistema social. $\bigcirc$ autor compreende o 
sistema social como uma pluralidade de atores individuais interagindo entre si numa situação que deve ter, pelo menos, um aspecto físico ou ambiental em comum. Esses atores estarão motivados a obter o máximo de gratificação nessa situação. Eles irão orientar suas ações pelo sistema de símbolos culturais que são compartilhados por todos os atores.

Parsons (1988) vinculou os sistemas sociais, culturais e de personalidade. Acreditava que, por meio da institucionalização, da internalização das "pautas de valor" e da socialização, haveria o êxito do sistema social, que poderia ser medido pelo grau de adaptação à norma, que não se trataria, apenas, de o indivíduo conhecê-la, mas também de se comprometer com ela.

Katz e Khan utilizaram as contribuições de Von Bertalanffy (1975) e o funcionalismo de Talcott Parsons (1988) para propor um modelo organizacional para empresas, considerando que todas as organizações são sistemas abertos. Chiavenato (2003) explica que a lógica que identifica as organizações como sistemas abertos tem sua atenção no empreendimento, porém reconhece a influência da organização e do ambiente, permitindo trocas constantes. "A organização é um sistema criado pelo homem e mantém uma dinâmica interação com seu meio ambiente, sejam clientes, fornecedores, concorrentes, entidades sindicais, órgãos governamentais e outros agentes externos. Influi sobre o meio ambiente e recebe influência dele" (CHIAVENATO, 2003, p. 479). Atuam diferentemente dos sistemas fechados que se baseiam num modelo mais "racional" de organização, que buscam a previsão exata dos acontecimentos, isolando-se, sem interação com o ambiente. $\bigcirc$ sistema aberto seria um sistema que se integra a outras unidades que se inter-relacionam, se interdependem e que buscam alcançar uma harmonia e atingir os objetivos estabelecidos pela organização e por seus integrantes. Além disso, "[...] trocam energia e informação com seus ambientes e são por eles influenciados" (CHIAVENATO, 2003, p. 288).

Assim, entre outras questões, é possivel afirmar que as funções, as normas e os valores são essenciais para o desenvolvimento da organização. Por meio deles, se pode reduzir a diversidade do comportamento humano e promover a integração ao ambiente. Além disso, por meio do "conceito de inclusão parcial" apenas são utilizadas as habilidades e conhecimentos necessários à organização, ignorando o que não é de interesse do sistema (CHIAVENATO, 2003). 
Várias são as críticas a essa compreensão administrativa na educação e muito surpreende que seja esta a noção de gestão que paira, atualmente, na visão dos profissionais da Secretaria de Estado da Educação de São Paulo. Evidencia-se, nessa mirada, a funcionalidade dos sistemas e a adaptação social dos indivíduos a eles. Há uma busca pela homogeneização, já que não pode haver dicotomias para o melhor andamento das organizações. Além disso, seguramente essa teoria impulsionou uma tendência a análises generalizadas, pois, se todos os sistemas são semelhantes, não há porque existir diversidade e, provavelmente, esta deverá ser eliminada.

Tendo em vista o entendimento de que todas as escolas fazem parte desse sistema, justifica-se a necessidade de a Supervisão de Proteção Escolar e Cidadania sistematizar e centralizar todas as ações. Não há espaço para os sobressaltos, para o inesperado, para as ações baseadas no conhecimento local. A Teoria Geral dos Sistemas (TGS) traz a compreensão da escola enquanto empresa e incorpora noções administrativas do mundo da produção para uma instituição que deveria ser regida por outra lógica. Acredita-se que, nesse aspecto, a Secretaria de Estado da Educação de São Paulo caminha na contramão do desenvolvimento das teorias de gestão escolar existentes.

A própria Secretaria de Estado da Educação de São Paulo desenvolveu, de 2005 a 2007, um Programa de Capacitação a Distância para Gestores Escolares - o Progestão - que visava à formação de lideranças democráticas. Foram nove módulos que tinham outra concepção de educação, ou seja,aproximar os gestores das discussões a respeito de uma gestão mais democrática e participativa. Além disso, o programa, igualmente, trazia uma discussão sobre as violências escolares. Especificamente, o Módulo V buscava preparar os gestores para a negociação de conflitos, a convivência democrática, a participação da comunidade na escola, entre outros (CARVALHO, 20011.

As atividades do Módulo V apontavam que a melhor forma de se gestar seria por meio da valorização do diálogo, da valorização do próprio aluno no espaço escolar, do sentimento de pertencimento por parte dos alunos e professores e a participação dos próprios atores na busca de negociação e amenização dos conflitos. A abordagem do Progestão não se assemelhava à concepção administrativa da educação que se apresenta nos documentos e depoimentos aqui analisados. Passaram-se alguns anos e a Secretaria de 
Estado da Educação de São Paulo apresenta um retrocesso em seu aporte teórico e político-educacional.

Tem-se,em um passado recente, o domínio dessas concepções administrativas dentro da educação e, a partir do contexto de abertura política nacional na década de 1980, muito se discutiu sobre o fato de ser inadequado transpor para a escola os modelos empresariais, considerando a natureza própria do processo pedagógico. As novas políiticas públicas passaram a defender a gestão escolar democrática e participativa com o foco na realidade escolar e em sua comunidade (SOUZA, 200 1). Além disso, a lógica que impulsiona o mercado empresarial, ou seja, o lucro, não pode ser aquela que orienta a gestão de instituições sociais, que devem se pautar pela garantia do direito dos sujeitos e, no caso da escola, pela garantia das condições de aprendizagem.

A partir do enfoque de uma gestão democrática e participativa, não cabe um enfoque sistêmico, derivado de uma concepção mecanicista, cujo objetivo principal é a produção, com maior eficiência e menos custos. O maior interesse, certamente, é no sistema e não nas pessoas, que são seres falíveis e que podem ser substituídas a qualquer momento pela organização.

Além disso, o Sistema de Proteção Escolar tenta impulsionar uma polí tica pública para a amenização da violência, em que segurança pública faz parte da educação. "Acho que essa é uma indicação de como desde o início o tratamento dado era, de fato, algo vinculado a questão mais propriamente dita de segurança" (SUPERVISOR, 2012, p.3). No entanto, os conhecimentos que a Segurança Pública possui sobre a violência são distintos dos objetivos educacionais nas escolas (ou deveriam ser). E isso é, igualmente, compreendido pelo representante do Sistema de Proteção Escolar, como pode ser evidenciado na fala a seguir:

Primeiro que não gosto muito desse termo: violência e escola. Existe, mas acho que não podemos dar caráter da Segurança Pública para esse ambiente, que é muito particular. Embora, é óbvio que existam situações de Segurança Pública que se manifestam ou no entorno ou mesmo dentro das escolas. E de maneira que a primeira grande conceituação em torno disso, se relacionou mais ao caráter de segurança das escolas (SUPERVISOR, 2012, p. 2). 
Mesmo sendo evidente esse limite necessário entre a escola e a segurança, o Sistema de Proteção Escolar entra nas escolas. De acordo com a legislação, o Sistema de Proteção Escolar indicava como seria possível garantir ao aluno o direito de um "[...] ambiente escolar democrático, tolerante, pacífico e seguro [...] zelar pela integridade física dos alunos e servidores [...] e preservar o patrimônio escolar, de maneira mais intensa nas escolas que indicassem maiores fatores de risco e vulnerabilidade. As escolas deveriam, segundo esse projeto, desenvolver "modelos de convivência pacífica e democrática" (SÃO PAULO, 2010).

Assim, esse projeto teve início com as ações que já foram apontadas: o Sistema Eletrônico de Registro de Ocorrência Escolar (2009), a publicação de dois manuais para as escolas públicas estaduais (2009) e posteriormente, em 2010 , regulamentou a função do Professor Mediador Escolar e Comunitário.

\section{Sistema Eletrônico de Registro de Ocorrência Escolar (ROE)}

A primeira ação da Supervisão de Proteção Escolar e Cidadania foi a criação do Sistema Eletrônico de Registro de Ocorrências Escolares (ROE).

160 Ferramenta criada em junho de 2009, regulamentada em 2010 e alocada no website da Fundação para o Desenvolvimento da Educação (SÃO PAULO, 2012 1, na qual os diretores deveriam registrar on-line ocorrências como conflito e grave indisciplina, agressões físicas, furtos, roubos, consumo e tráfico de drogas, formação de gangues, ameaças, vandalismos, danos patrimoniais, crimes e atos infracionais, entre outros, favorecendo o controle da Secretaria de Estado da Educação de São Paulo (SÃO PAULO, 2012).

Segundo o Planejamento Escolar $2010^{3}$ do Sistema de Proteção Escolar, o objetivo do Registro de Ocorrências Escolares seria o "[...] registro e mapeamento das situações de insegurança e indisciplina que afetam as escolas da rede pública estadual" (DERL, 2010 , p. 4). O Registro de Ocorrências Escolares se constituía num banco de dados que demonstraria, estatisticamente, as unidades mais problemáticas, que necessitavam de ações reparadoras. Seria possível conhecer o cotidiano das escolas e, de acordo com o histórico de cada instituição, a proposta seria que, futuramente, equipes multidisciplinares pudessem intervir, propondo ações preventivas e saneadoras desenvolvidas pela Secretaria de Estado da Educação de São Paulo, articulando-se com 
outras instituições que auxiliam a escola na proteção escolar e/ou desenvolvendo projetos pedagógicos.

De acordo com o Planejamento Escolar e a Resolução SE n 19, de 12 de fevereiro de 2010, o sistema Registro de Ocorrências Escolares (ROE) era, apenas, informativo e confidencial, não prejudicando o aluno ou a escola que efetuava o registro. Ainda, no mesmo documento, salientava-se que as informações registradas serviriam à Supervisão de Proteção Escolar e Cidadania ${ }^{4}$ para o planejamento de ações de suporte às escolas mais vulneráveis.

Para o Supervisor, havia a necessidade de a Secretaria da Educação conhecer as manifestações de violência que ocorriam em sua rede. Havia o conhecimento de alguns problemas, de situações isoladas e, assim, surgiu a necessidade de organizar o conjunto das informações do que vinha acontecendo, em quais regiões etc.

Não que ela exista hoje também, mas melhorou. É sempre um pouco subjetiva a compreensão de como se dá os problemas de conflito, convivência e violência, mas era um nível de subjetividade muito maior do que existe hoje, apesar de que nunca transcenderemos algum nível de subjetividade (SUPERVISOR, 2012, p. 2).

No entanto, não foi possível obter um mapeamento do que acontece nas escolas estaduais por meio desse instrumento devido a várias situações que ocorreram ao longo do tempo:

- Em primeiro lugar, o trabalho excessivo da direção da escola impede que alguns diretores se preocupem em inserir dados e informações em um sistema, sobretudo se esse instrumento não oferece um retorno efetivo para a escola. Segundo o Supervisor, a Supervisão de Proteção Escolar e Cidadania busca atender todas as ocorrências, mas não consegue devido à demanda maciça do Estado.

- Segundo, porque como não há compreensão clara dos objetivos do Registro de Ocorrências Escolares, há diretores que não efetuam registros e outros que registram em demasia. O Supervisor fornece alguns exemplos: alguns diretores temem registrar as ocorrências de suas escolas por acreditarem que demonstrarão ineficiência e falta de controle da situação; outros diretores fazem registros excessivos por acreditarem que farão jus ao Adicional de Local de Exercício (A.L.E), uma gratificação salarial relativa à vulnerabilidade social que, na 
verdade, é definida por critérios da Fundação Seade, do índice de vulnerabilidade social paulista.

- Em terceiro lugar, a questão que o Supervisor destaca como subjetividade, mas que se acredita que é relativo para a compreensão que os profissionais da educação têm sobre a violência. Ou seja, o entendimento que cada diretor, no caso, faz das situações e atitudes que devem ser consideradas como violências ou não, e que o Registro de Ocorrências Escolares define como "infração5".

que nos interessa é conhecer o dano ou vandalismo que tem um impacto concreto e muito daninho no cotidiano escolar. Mas, temos casos de diretor que registra como dano e vandalismo 'João e Maria, com um coraçãozinho na porta do banheiro', sabe? A rigor, a rigor é um dano, porque é um patrimônio público. Mas, enfim, em uma escola isso não é estatística. Por exemplo, você tem um tipo relacionado à agressão sexual e também aparece de tudo, desde questões sérias, que ainda bem que são raras, mas de qualquer maneira, que é o que nos interessa saber, caso ocorra, e até ligadas ao desenvolvimento da sexualidade, que é natural. Era para a escola já ter domínio. Se há o registro como agressão sexual, isso gera uma estatística totalmente preocupante (SUPERVISOR, 2012, p. 5).

Objetivo inicial era criar um banco de dados estatísticos que demonstrasse um quadro da violência nas escolas no Estado de São Paulo. Porém, sua aplicação demonstrou que esse objetivo não poderia ser alcançado. $\bigcirc$ Supervisor compreende que o Registro de Ocorrências Escolares não serve como ferramenta de apreensão estatística, mas que seu potencial estaria em utilizá-lo como forma de comunicação, prestando um serviço para as escolas. Ele acredita que, se o Registro de Ocorrências Escolares for utilizado dessa forma, poderá ter maior adesão a esse sistema e a compreensão do que está acontecendo com relação a violência nas escolas.

Segundo o Supervisor, há muita discussão na Secretaria de Estado da Educação de São Paulo sobre como o Registro de Ocorrências Escolares pode ir além dos seus objetivos e ser um sistema que cria um meio de comunicação direto da escola com a sua Diretoria de Ensino e com a Secretaria de Estado da Educação de São Paulo. Além disso, uma ferramenta on-line auxiliaria 
na diminuição dos documentos escritos, enviados à Secretaria de Estado da Educação de São Paulo e da morosidade das respostas aos processos.

Conforme informou o Supervisor, embora com uma capacidade reduzida de recursos humanos, todas as ocorrências registradas são lidas diariamente, passando, posteriormente, por uma classificação de gravidade, por meio daquilo que é possível aferir pelo que foi registrado. A maior parte das ocorrências é, apenas, lida, porque não é de grande gravidade. Outra parte é arquivada. Observa-se a eventualidade de ocorrências semelhantes. Se voltarem a acontecer, a Supervisão de Proteção Escolar e Cidadania que possui sua sede dentro da Secretaria da Educação na cidade de São Paulo, entra em contato com a escola oferecendo suporte e, eventualmente, realizando uma visita à escola. Contudo o retorno para os diretores ocorre apenas em ocorrências de maior gravidade, pois, como já foi dito, a capacidade da Supervisão de Proteção Escolar e Cidadania é reduzida.

Sistema de Proteção Escolar, por meio do Registro de Ocorrências Escolares, buscaria oferecer subsídios para a direção da escola, pois, segundo - Supervisor, os diretores estão despreparados para lidar com situações de violência. "Além dele se sentir sozinho, ele se sente despreparado e ele está despreparado" (SUPERVISOR, 2012, p. 6).

Essas afirmações propõem reflexões sobre essa temática da formação do gestor. Se há clareza por parte da Secretaria de Estado da Educação de São Paulo de que, o diretor necessita de preparo para gerenciar seus próprios conflitos, por que atribuir a Segurança Pública um papel que deveria ser de um gestor de escola "bem preparado" para gerenciar a convivência escolar?

Além disso, esse problema posto pelo Supervisor demonstra que se a Teoria dos sistemas entende que todas as escolas possuem as mesmas características e devem possuir diretrizes iguais, seguramente as orientações vindas da Secretaria de Estado da Educação de São Paulo resolveriam todos os problemas nas diferentes escolas, em diferentes lugares do Estado de São Paulo. Assim, há uma falha, nessa perspectiva de sistema, visto que ela não pode prever problemas locais, cotidianos e específicos.

Há grande preocupação do Estado conhecer e controlar as ocorrências no sistema escolar. Inúmeras planilhas demonstram a presença, a ausência, as notas, a participação, a situação financeira familiar, os laudos médicos e psicológicos de alunos e professores, entre outros. E com o Registro 
de Ocorrências Escolar, esse faz uma tentativa de aferir o comportamento e as atitudes de uma comunidade de determinada escola estatisticamente. Os aparatos tecnológicos desempenham um papel fundamental nessa nova construção do conhecimento de controle das informações. Por meio do Registro de Ocorrências Escolares, o Estado busca mais um instrumento, desta vez, via internet, para vigiar e controlar os comportamentos díspares, na tentativa de se disciplinar e controlar.

Essa vigilância e controle não fazem parte apenas de nossa vida contemporânea. De acordo com Foucault (1987, p. 1 18), a vigilância desempenhou, desde o século XVII, o papel principal no funcionamento das práticas disciplinares. Segundo o autor, "esses métodos que permitem o controle minucioso das operações do corpo, que realizam a sujeição constante de suas forças e thes impõem uma relação docilidade-utilidade, são o que se pode chamar as 'disciplinas'" (FOUCAULT, 1987, p. 118). Assim, por meio dos exercícios, do treinamento, entre outros, esses corpos eram impulsionados a atingir sua força útil, exercendo-se uma anátomo-política disciplinar sobre eles.

Já no final do século XVIII e início do século XIX, o poder passa a se exercer em um domínio mais coletivo, suprindo a necessidade de aperfeiço164 amento do processo disciplinar. $\bigcirc$ poder exercido sobre o corpo individual passa a possuir, igualmente, uma tecnologia sobre a vida. Essa nova técnica de poder não estará dirigida diretamente ao corpo, mas a vida dos homens e "[...] não ao homem-corpo, mas ao homem vivo, ao homem ser vivo; no limite, se vocês quiserem, ao homem-espécie" (FOUCAULT, 2005, p. 289). Essa nova tecnologia de poder não suprime a tecnologia disciplinar, irá integrá-la e modificá-la no sentido de aprimorar sua escala, passando a uma escala global, por meio de instrumentos diferenciados tratando da multiplicidade dos homens.

Deste modo, após a anátomo-política disciplinar sobre os corpos, surge essa nova técnica, chamada por Foucault (2005, p. 292) de "biopolítica" da espécie humana. Com a biopolítica um novo personagem se destaca, para além do indivíduo e seu corpo, resultado de um "[...] corpo-múltiplo, corpo com inúmeras cabeças, se não infinito pelo menos necessariamente numerível" (FOUCAULT, 2005, p. 292), ou seja, a "população".

Os interesses da biopolítica são notadamente econômico-políticos, pertinentes somente em nível de massa, e se preocuparão em categorizar essa 
população observando, durante um determinado período temporal, os fenômenos em série que tratam da saúde pública, da segurança, da higiene, entre outros; buscando normalizar o corpo. Essa nova técnica de poder, esse "biopoder" sobre a população, irá exercer uma regulação política por meio de estatísticas, previsões, medições globais, na tentativa de se obter uma rentabilidade cada vez maior.

A intenção seria de estabelecer, acima de tudo, mecanismos reguladores para fixar um equilíbrio, "uma espécie de homeostase" sobre o aleatório, otimizando um estado de vida. Esses mecanismos tentariam maximizar as forças, diferentemente de um treinamento individual, sobre o próprio corpo, atingindo estados globais de regularidade (FOUCAULT, 2005).

$\bigcirc$ Registro de Ocorrências Escolares dessa maneira trata de manter essa regulamentação por meio de dados estatísticos e preservar o equilíbrio também desejado pela Teoria Geral dos Sistemas (TGS), em busca de uma rentabilidade cada vez maior. A "homeostase", mencionada por Foucault (2005), trata de um elemento importante na TGS e é igualmente chamada de "estado firme" nas teorias administrativas empresariais (CHIAVENATO, 2003). Para se alcançar esse estado firme ou estado de equilíbrio, o sistema deve buscar manter seu "status quo interno" por meio da "[...] unidirecionalidade ou constância de direção [...]" (mesmo surgindo mudanças, os objetivos devem ser atingidos encontrando-se outros meios) e "progresso" com relação ao fim (CHIAVENATO, 2003, p. 480). Seria um equilíbrio dinâmico resultante da autorregulação, do autocontrole. "Todo mecanismo homeostático é um dispositivo de controle para manter certa variável dentro de limites desejados [...]" ou seja, os limites de normalidade (CHIAVENATO, 2003, p. 421).

Assim, entende-se que o Sistema de Proteção Escolar, por meio do Registro de Ocorrências Escolares e outros instrumentos e que será abordado posteriormente, tinha a intenção de utilizar a disciplina para desenvolver a ideia do equilíbrio da homeostase, estabelecendo os comportamentos e normas desejáveis (e aceitáveis) para o padrão de controle. A norma, para Foucault (2005, p. 302), é o "[...] elemento que vai circular entre o disciplinar e o regulamentador, que vai se aplicar, da mesma forma, ao corpo e à população, que permite a um só tempo controlar a ordem disciplinar do corpo e os acontecimentos aleatórios de uma multiplicidade biológica". E para que essa normalização aconteça, a polícia irá exercer um papel fundamental. Para Foucault (2005), a polícia é um aparelho disciplinar que adquire uma 
dimensão estatal, tornando-se, igualmente, um aparelho do Estado, ou seja, possui seu mecanismo disciplinar do corpo e possui seu mecanismo regulamentador da população. Esses mecanismos não se excluem; eles se articulam entre si.

Quando a polícia, enquanto aparelho disciplinar e aparelho regulamentador estatal, adentra a educação, traz os mecanismos do biopoder e foca não somente no indivíduo, mas principalmente na normalização da multiplicidade, da população, ou seja, a normalização da "rede", do "sistema", como um conjunto de escolas. Daí a grande preocupação com as estatísticas: "[...] isso gera uma estatística totalmente preocupante" (SUPERVISOR, 2012, p. 5). Esses mecanismos de poder são facilmente absorvidos pelos profissionais da educação que, há anos, possuem seus méritos e salários atribuídos de acordo com dados estatísticos (Índice de Desenvolvimento da Educação do Estado de São Paulo - Idesp, por exemplo). Desse modo, quando surge uma nova ferramenta para aferir dados, rapidamente se remetem a essa lógica, como foi dito pelo Supervisor com relação aos diretores que acreditavam que receberiam um bônus em virtude do registro demais ocorrências.

A preocupação em se aferir os dados leva a busca por tecnologias 166 cada vez mais sofisticadas, aparatos tecnológicos e as informações são cada vez mais precisas para manter as normas. Atualmente, nas escolas públicas paulistas, já é possível obter, em tempo real, os dados necessários para se avaliar o desempenho de cada aluno em diversos setores de sua vida escolar. Por meio do Registro de Ocorrências Escolares, há uma tentativa para que o controle disciplinar se amplie, se aprofunde e o poder regulamentador se estabeleça, embora, muitas vezes, esse poder escape pelas brechas, não se estabeleça por completo, como, por exemplo, quando o Supervisor declara que esse instrumento não é ideal como meio estatístico. No entanto, o Sistema de Proteção Escolar tenta usar esse instrumento de maneira "produtiva". Assim, o Supervisor depõe que essa ferramenta não será utilizada apenas no sentido de aferir desvios individuais, de regulamentar uma população, mas também detectar as escolas que mais necessitam de auxílio, orientando-as e acompanhando-as.

Acredita-se que não é possível realizar uma análise sem se pensar na ambiguidade existente em toda "verdade". Para Foucault (1987), os efeitos de poder não são apenas negativos, em termos de somente excluir, reprimir, censurar etc. "Na verdade o poder produz; ele reproduz realidade; produz 
campos de objetos e rituais da verdade. $\bigcirc$ indivíduo e o conhecimento que dele se pode ter se originam dessa produção" (FOUCAULT, 1987, p. 161). Assim, se busca, igualmente, um conhecimento das escolas estaduais paulistas e caminhos para se trilhar na tentativa de amenizar a violência nas escolas.

Observa-se, igualmente, a ambiguidade no depoimento do representante do Sistema de Proteção Escolar que transita entre um olhar educacional e um olhar policial (capturado pelo biopoder). Seguramente, seu olhar não poderia deixar de estar viciado por sua experiência na Segurança Pública, que exerce um papel extremo de disciplinarização, regulamentação e normalização.

fato é que a Secretaria da Educação elege esse papel extremo (disciplinar e regulamentador) para controlar suas escolas. Vários são os motivos que podem ser elencados para a inserção da Segurança Pública na Educação: medo que tudo saia fora do controle, questões políticas, responder a casos de violência que cada vez são mais midiatizados, a crença que não há profissionais competentes na área da Educação, etc. Porém, acredita-seque a intenção é que o poder se estabeleça de maneira massiva que nada escape ao seu controle.

Mesmo com essa intenção, diversos problemas com relação à violência continuam ocorrendo nas escolas após a implantação do Sistema de Proteção Escolar. $\bigcirc$ poder tenta ser massivo, entretanto os problemas acontecem nos "microespaços" do cotidiano, são pontuais, específicos e não podem ser generalizados e centralizados. Há necessidade de mais pesquisas sobre o cotidiano das escolas e a preocupação com a formação de nossos gestores visando ampliar sua visão como profissionais da educação, sem permanecer num papel extremamente burocrático, compreendendo a complexidade dos fenômenos e as possibilidades de atuação na escola. No entanto, mais ações da Supervisão de Proteção Escolar e Cidadania previam a normalização e padronização dos espaços escolares como se verá mais adiante.

\section{"Manual de proteção escolar e promoção da cidadania" e "normas gerais de conduta escolar"}

Dando continuidade a essa política, a Secretaria de Estado da Educação de São Paulo, no mês de agosto de 2009, lançou dois manuais de apoio para as escolas públicas paulistas: o "Manual de Proteção Escolar 
e Promoção da Cidadania" e as "Normas Gerais de Conduta Escolar" ISÃO PAULO, 2009 e 2009a). Em sua apresentação, os manuais teriam como principal objetivo subsidiar as escolas públicas para conhecer os direitos civis, constitucionais e alguns conceitos relacionados ao sistema de segurança. Além disso, pretendiam fornecer informações relativas à natureza das atribuições e competências das diversas instâncias a serem mobilizadas ao se depararem com os conflitos na escola. Esses manuais se constituiriam em um "[...] indispensável referencial comum a todas as escolas [...]" públicas paulistas (SÃO PAULO, 2009, p. 5).

Segundo o Supervisor, o "Manual de Proteção Escolar" é inspirado em uma produção equivalente a do Distrito Federal. É um manual com o conteúdo adaptado por meio de uma parceria, não se tratando da mesma publicação. Já as "Normas Gerais de Conduta Escolar" foram elaboradas no interior da Secretaria de Estado da Educação de São Paulo com base no entendimento de que não havia diretrizes para os regimentos escolares.

Na verdade você tem um parecer do Conselho Estadual da Educação, que diz que deve haver regimentos escolares, muito genericamente relata mais ou menos o que eles devem tratar, mas no máximo um parágrafo isso. Como a Secretaria passou um tempo sem trabalhar especificamente essa questão, o que acontece é que muitas escolas caíram totalmente em desuso, os seus regimentos e outras, continuaram usando, mas ficou totalmente desatualizada, de pouca apropriação pela Unidade Escolar. Outro problema que existia é que percebemos que não havia uma padronização em relação a esses regimentos. Então em uma rede estadual poderia haver regimentos totalmente contraditórios um com o outro. O que não faz muito sentindo, se você está com uma gestão centralizada de uma rede. Apesar da necessidade de desenvolver o aspecto descentralizado de gestão, é fundamental em uma rede deste tamanho, deve ter algumas diretrizes mínimas para que não tenhamos situações totalmente díspares em uma mesma rede de ensino (SUPERVISOR, 2012, p. 4).

Há uma tentativa de padronização, de estabelecer normas iguais a realidades diferentes. A abordagem é da centralização, de uma teoria administrativa, ao mesmo tempo que o Supervisor cita a descentralização, demonstrando que não desconhece a legislação vigente referente à gestão democrática e participativa. Porém, o teor continua o mesmo: a ideia de rede 
associada ao sistema. Sabe-se que as situações e as ações são díspares porque existem realidades diferentes nas escolas. Assim, não há como padronizar ações, sobretudo quando elas se referem às violências na escola.

Foram publicadas essas normas, que não é de maneira alguma um código, que muitas vezes algumas pessoas tendem a usar dessa maneira. Não é um código que se atribui punições específicas a ações específicas. Fez isso: suspensão! Fez isso: expulsão! Não é isso! A ideia era oferecer diretrizes para que as escolas a partir delas adaptem seus regimentos, baseada numa correlação entre direitos e deveres de todos os seguimentos escolares (SUPERVISOR, 2012 , p. 4).

Há certa contradição na fala do Supervisor, que busca amenizar o conteúdo do documento, assim como outras ações da Secretaria de Estado da Educação de São Paulo. Na verdade, não são publicadas diretrizes, e sim normas que devem ser seguidas à risca pelos diretores, como o próprio documento estabelece em sua introdução. "Cada estabelecimento de ensino deve adotar estas Normas Gerais de Conduta Escolar como referência, porém medidas ou procedimentos adicionais, que não afrontem o disposto nelas, podem ser adotados individualmente pelas escolas, havendo aprovação do Conselho Escolar" (SÃO PAULO, 2009a, p. 5).

A preocupação de o Supervisor tornar o documento menos intenso, ao afirmar que são apenas diretrizes, deve-se ao fato de as "Normas Gerais de Conduta Escolar", além de apresentarem as regras que deviam ser respeitadas, os direitos e as responsabilidades dos alunos - normatizando condutas desejáveis e indesejáveis no âmbito escolar -, apresentavam, igualmente, as medidas disciplinares que as escolas deveriam tomar no caso de comportamentos indesejáveis, incluindo-se suspensão de até dez dias e transferência compulsória para outro estabelecimento (SÃO PAULO, 2009a). Ou seja, punições que desrespeitam o direito do aluno de acesso e permanência na escola, de acordo com os aportes legais como o Estatuto da Criança e do Adolescente (BRASIL, 1990) e a Lei de Diretrizes e Bases da Educação - Lei n 9.394, de 20 de dezembro de 1996 (BRASIL, 1996) e as medidas mais preventivas, propriamente do campo educacional, foram apresentadas somente no final do material e de forma superficial, como algo adicional. 
Já o "Manual de Proteção Escolar e Promoção da Cidadania" apresentava em torno de cem perguntas e respostas sobre diversos problemas que ocorrem nas escolas. Na maioria das respostas, as medidas punitivas indicadas são severas e colocam a força policial como participante desse processo educativo. Em muitas situações a polícia deveria ser acionada. Acredita-se que, se as respostas que esse manual oferece fossem seguidas, seria necessário instalar postos policias dentro das escolas. De acordo com o Manual, se houver maior gravidade ou "reincidência" nos casos de agressões físicas e verbais por parte dos alunos, uso de drogas, de álcool, depredação do patrimônio, furto, entre outros, a Polícia Militar deve ser acionada. As formas da equipe lidar com os problemas relacionados a conflitos se pautam, em sua maioria, em acionar o Conselho Tutelar e a Polícia Militar.

Essas diretrizes, porém, como já foi destacado, estavam voltadas mais para a área da segurança pública que propriamente da educação. Ao processo educativo e preventivo não possui quase nenhum espaço dentro desse material. Obviamente, existem situações que fogem ao controle da escola e não pertencem mais a sua alçada. No entanto, a maior parte das manifestações de violência apresentadas acima, que a própria escola poderia lou em 170 grande parte já o faz) tomar um posicionamento educativo, pois são situações que pertencem à área educacional e não à área da segurança pública.

Em trabalho produzido por Possato e Scotuzzi (2009), faz-se uma discussão sobre esses manuais e constata-se que eles apresentam instrumentos autoritários e discriminatórios, instigando o caráter punitivo e controlador para com os jovens que não seguem os modelos e normas estabelecidos pelas instituições escolares. Esses manuais determinavam padrões de conduta para estudantes e orientavam os educadores que acionassem a polícia, registrassem boletins de ocorrência, notificassem as autoridades, estimulando um posicionamento de denúncia e de culpabilização. Acredita-se que há mais espaço para punir os atos de indisciplina, que, de fato, elaborar medidas preventivas e reparadoras. Percebe-se que há um desconhecimento das teorias educacionais, desenvolvidas, ao longo dos anos, sobre a temática ${ }^{6}$ e o retorno a um sistema punitivo e controlador, utilizado desde o século XVII (FOUCAULT, 1987).

Guimarães (2005) alerta sobre a incapacidade que, muitas vezes, a ordem policial possui de respeitar um "consenso orgânico" ${ }^{7 "}$ estabelecido na escola e de respeitar a diversidade. Para a autora, representa uma grande 
ameaça que ronda o totalitarismo das instituições. Com as ordens sendo impostas, estabelecidas e não negociadas e incorporadas, vão criando-se controles constituídos em um "[...] modelo abstrato onde ordem e respeito exigem não uma 'organicidade diferencial', mas uma unanimidade que precisa de indivíduos isolados para alcançar uma domesticação pacífica e mortal".

Muitos são os estudos que apresentam propostas ou experiências para que as escolas consigam atuar em contextos de violências sem o uso da força externa da polícia. Amparam-se na formação docente como meio de encontrar procedimentos pedagógicos e práticas diferenciadas para lidar com problemas cotidianos (ROYER, 2003), por meio do diálogo e da Mediação de Conflitos (ORTEGA-RUIZ; DEL REY, 2002), na participação dos alunos na vida pública, desenvolvendo a autonomia moral (ZALUAR; LEAL, 2001), sobretudo em uma gestão democrática e participativa, inserindo, efetivamente, alunos e comunidade na vida escolar como forma de encontrar soluções conjuntas para os problemas cotidianos (ABRAMOVAY; RUA, 2002), na discussão das relações de poder (GUIMARÃES, 2005), entre muitos outros estudos.

No entanto, nos documentos oficiais, aqui discutido, esses estudos e diversas experiências foram considerados adicionais ou meramente inexploradas. No contexto apresentado pelos documentos, a "violência institucional"8 é desconsiderada, pois as violências aparecem como unilaterais, marcadas, principalmente, pelas violências dos alunos contra a instituição. Com isso, impulsionam um quadro de vigilância/punição/exclusão do aluno que não se enquadra nos padrões de normalidade estabelecidos pela escola.

Esses documentos amparavam-se, sobretudo, em um mecanismo disciplinar, embora o Sistema de Proteção Escolar igualmente buscasse estabelecer uma regulamentação - a normatização e normalização dos alunos. Todavia, seu aspecto disciplinar aparecia de modo extremamente evidente, apresentando sua fase mais repressiva e punitiva. Nada estava oculto, como normalmente ocorre com os mecanismos do biopoder. Acredita-se que essa visão repressiva também foi percebida pela Secretaria de Estado da Educação de São Paulo que está reavaliando esses documentos.

Temos críticas e estão sendo revisados. Temos contato com uma consultoria que está fazendo revisão desses materiais. Acho que os referenciais cumpriram um papel na época, foi uma ação importante e teve o aspecto positivo de ajuda. Só que é um trabalho vivo, ele tem que evoluir. Acho que hoje no que a gente já trabalhou 
com isso, ele tem que melhorar muito e a gente inclusive tem uma consultoria para ouvir mais a rede e oferecer um material que esteja mais de acordo com o que eles necessitam de fato (SUPERVISOR, 2012 , p. 4).

Esses Manuais, porém,foram enviados para mais de 5,4 mil escolas da rede estadual de São Paulo, que atendem, em média, 4,7 milhões de alunos, disseminando essa normatização e normalização dos comportamentos tanto dos alunos, como dos diretores, que devem ser padronizados em suas atitudes diante de fatos semelhantes. Disseminaram, igualmente, uma maneira extremamente repressora de se pensar as violências escolares, visto que traziam uma visão de culpabilização e até de judicialização dentro do processo educativo.

Logo após o lançamento dos manuais, a Resolução SE n 19 de 12 de fevereiro de 2010 instituiu, legalmente, o Sistema de Proteção Escolar como um conjunto de ações e uma política da Secretaria de Estado da Educação de São Paulo. Criou-se a função do Professor Mediador Escolar e Comunitário que passou a ser o representante do Sistema de Proteção Escolar nas escolas estaduais paulistas.

\section{Considerações finais}

Faz-se essa crítica da abordagem sistêmica do "Sistema de Proteção Escolar" com fulcro no referencial teórico de Foucault na tentativa de desvendar não somente as técnicas disciplinares - que atingem os alunos nas escolas por meio das disciplinas do corpo, individualmente - como também as regulamentações que se cumprem com o controle da vida coletiva, ou seja, o biopoder - exercendo-se como um controle mais geral sobre todas as escolas públicas do Estado de São Paulo para prever riscos. Por meio da norma, das regulamentações, os mecanismos disciplinares e o biopoder se articulam com a individualização e o conjunto ao mesmo tempo.

No decorrer do texto, emergiu uma política pública educacional com o objetivo de amenizar as violências escolares no seio da Segurança Pública, fortemente vinculada a uma visão policial e administrativa. A Teoria Geral dos Sistemas serviu de guia para compreender que a visão da escola foi concebida como a de uma empresa. Conforme discutido anteriormente, legal e teoricamente, já constata-se um avançocom relação às teorias de gestão e de 
convívio escolar. As concepções administrativas da educação já deveriam ter sido abandonadas dando espaço à gestão democrática e participativa.

Essa compreensão direcionaria para outro viés qualquer proposta de uma política pública para se amenizar as violências escolares. Pode-se citar, como exemplo, o estudo feito por Abramovay e Rua (2003), cuja pesquisa apresenta catorze estabelecimentos de ensino públicos que conseguiram realizar experiências inovadoras com relação às violências escolares, apontando que o posicionamento da gestão escolar é fundamental para que mudanças positivas ocorram na escola. Há uma importância expressiva da atuação do gestor junto ao coletivo da escola, sobretudo ao modificar seu modo convencional de administrar, de gerenciar os conflitos, promovendo o diálogo e a valorização dos alunos e professores. Para isso, nunca é demais insistir: é necessário o conhecimento da realidade local, a aproximação com a comunidade e fortalecimento da autonomia da escola.

Assim, a lógica da gestão democrática e participativa não se relaciona ao enfoque sistêmico, a uma concepção mecanicista cujos fins são os resultados, a eficiência, os custos etc. Em educação,é importante se preocupar com os meios, com os processos, com as relações pessoais. Em educação o maior interesse deveria ser os indivíduos e suas subjetividades. Não é possível, como na Teoria dos sistemas, estabelecer diretrizes, orientações e normas iguais a todas as escolas quando se trata, sobretudo, dos problemas que envolvem as relações humanas. Porém, percebe-se a tentativa do Estado em estabelecer os mecanismos do biopoder, regulamentando e normatizando toda a vida escolar.

Além disso, existe a preocupação como vínculo cada vez mais recorrente que se tem estabelecido entre a polícia e as escolas no Brasil, sobretudo para "conter" as violências escolares. No estado de São Paulo, o fato de uma Secretaria de Educação responsabilizar esse aparelho de estado, a polícia, por uma política que deveria ser educacional, é bastante significativo. Essa escolha não é aleatória, é uma escolha intencional que demonstra representativamente a política pública de educação para as classes populares nesse Estado.

Isso evidencia que, para o Estado, a educação seria um "caso de polícia", que a população deve ser conduzida por meio, não apenas, de práticas disciplinares, mas, sobretudo, que o poder seja estabelecido de forma plena, 
normatizando, regulamentando e controlando suas vidas. Nesse contexto, sobretudo os alunos que não se enquadram nesses padrões de normalidade, continuam sendo excluídos do sistema, sendo catalogados no Registro de Ocorrências escolares, e transferidos, compulsoriamente, por meio das Normas Regimentais, sendo encaminhados ao Conselho Tutelar ou a Polícia Militar, enfim, incluindo-se em dados estatísticos de abandono escolar.

Não se pode esquecer que, não obstante todas essas críticas, Foucault (1990, p. 148) considera que o poder irá se exercer fundamentalmente e que nada poderá detê-lo. Ademais, se ele "[...] só tivesse a função de reprimir, se agisse apenas por meio da censura, da exclusão, do impedimento, do recalcamento, à maneira de um grande superego, se apenas se exercesse de um modo negativo, ele seria muito frágil". Dessa forma, o poder possui sua face positiva, no sentido do desejo e do saber. Por meio dele, se produzem discursos, saberes, prazeres, se incita, se incentiva, se suscita, se faz falar, se faz ouvir. Assim, essa política pública, igualmente, poderá produzir conhecimento sobre a condição de nossas escolas públicas.

Além disso, no seio desse saber-poder, poderão surgir práticas de liberdade, pois é, por meio das relações de poder, que nascem essas possibilidades de resistência e de luta, e que conduzem a um novo pulsar. Espera-seque essas políticas públicas que tentam massificar o indivíduo e suas subjetividades impulsionem a novos olhares, a novas propostas e que se possa construir novas formas de ser e fazer a educação deste país.

\section{Notas}

1 Este artigo faz parte da tese de doutorado $\bigcirc$ "Professor Mediador Escolar e Comunitário": uma mirada a partir do cotidiano escolar, de minha autoria sob a orientação da Profa. Dra. Dirce Dianira Pacheco e Zan (POSSATO, 2014).

2 Por preferência pessoal, manterei no anonimato o supervisor entrevistado, embora não tenha sido uma exigência, tampouco um compromisso assumido na entrevista. Essa escolha deve-se ao fato do depoimento representar uma fala institucional e não pessoal, sendo representativa da Secretaria de Estado da Educação de São Paulo. Boa parte deste artigo foi construída por meio da narrativa do "Supervisor", obtida em entrevista realizada em maio de 2012 , visto que ainda não existem muitos documentos disponíveis ao público sobre a elaboração e implementação do Sistema de Proteção Escolar.

3 Documento que tive acesso por meio da Diretoria de Ensino de Limeira para ser analisado.

4 Equipe multidisciplinar que gerencia o Sistema de Proteção Escolar na Secretaria de Estado da Educação de São Paulo. Parte dessa equipe pertence à Secretaria da Segurança Pública. 
5 Registro de ocorrências escolares organiza as categorias de registrar como "infração", que seguramente traz inspiração do direito penal.

6 Charlot, 2002; Debarbieux, Blaya, 2002; Guimarães, 2005; Maffesoli, 1981; Abramovay, Rua, 2002; entre outros..

7 Para Guimarães (2005. p. 19), o consenso orgânico para Maffesoli (1981) integra uma "perspectiva paradoxal" (p. 13). A "solidariedade orgânica" se expressa na vida cotidiana mantendo os laços sociais por meio da duplicidade que, como uma forma de resistência, permite a "coesão" do grupo. Não seria unanimidade, tampouco uma "solidariedade mecânica", que irá separar, isolar os indivíduos e torná-los " [...] independentes de um poder desvinculado da vida social, mas de uma organicidade fundada na multiplicidade da força coletiva que, escapando da diferenciação que os poderes instituídos tentam impor, garante a sobrevivência do social".

8 De acordo com o referencial teórico de Maffesoli (1981), a "violência institucional" se daria na lógica de dominação e de poder que os poderes instituídos impõem aos indivíduos, na tentativa de planificar e transformar a pluralidade em homogeneidade.

\section{Referências}

ABRAMOVAY, Miriam; RUA, Maria das Graças. Violências nas escolas. Brasília: UNESCO, 2002.

BRASIL. Estatuto da criança e do adolescente. Lei n. 8.069, de 13 de julho de 1990. Diário Oficial [da] República Federativa do Brasil, Poder Executivo, Brasília, DF, 16 jul. 1990. Seção 1, p. 13563. (Retificada no Diário Oficial da União, Seção 1, de 27 de agosto de 1990, p. 185511.

Lei de Diretrizes e Bases da Educação. Lei n. 9.394, de 20 de dezembro de 1996. Estabelece as diretrizes e bases da educação nacional. Diário Oficial [da] República Federativa do Brasil, Poder Executivo, Brasília, DF, v. 134, n. 248, Seção 1, 23 dez. 1996, p. 27833.

CAPRIGLIONE, Laura; KAWAGUTI, Luis. Alunos brigam, depredam escola e apanham da PM São Paulo. Folha de S. Paulo. São Paulo, p. C 1.13 nov. 2008. (Seção Cotidiano). Disponível em: http://www 1.folha.vol.com.br/fsp/cotidian/ff 1311200801 .htm. Acesso em: 12 fev. 2014.

CARVAlHO, Maria Celeste da Silva. Progestão: como construir e desenvolver os princípios de convivência democrática na escola? Brasília: ConSed - Conselho Nacional de Secretários de Educação, 2001.

CHARLOT, Bernard.A violência na escola: como os sociólogos franceses abordam essa questão. Revista Sociologias, Porto Alegre,n. 8, p. 432-443, jul./dez. 2002. 
Um sistema para se proteger da escola

CHIAVENATO, Idalberto. Introdução à teoria geral da administração: uma visão abrangente da moderna administração das organizações. Rio de Janeiro: Elsevier, 2003.

DEBARBIEUX, Eric; BLAYA, Catherine. Violência nas escolas e políticas públicas. Brasília: UNESCO, 2002.

FOUCAULT, Michel. Vigiar e punir. Tradução Raquel Ramalhete. Petrópolis: Vozes, 1987. Microfísica do poder. Tradução Roberto Machado. Rio de Janeiro: Graal, 1990.

Em defesa da sociedade: course no Collége de France (1975-1976). Tradução Maria Ermantina Galvão. São Paulo: Martins Fontes, 2005.

FREITAS, Carolina.Alunos provocam quebra em escola onde Serra estudou. O Estado de S. Paulo, 14 maio 2009. Disponível em: http://sao-paulo.estadao.com.br/noticias/ geral, alunos-provocam-quebra-quebra-em-escola-onde-serra-estudou,370945. Acesso em: 12 fev. 2014.

GUIMARÃES, Áurea Maria. A dinâmica da violência escolar: conflito e ambiguidade. Campinas: Autores Associados, 2005.

MAFFESOLI, Michel. A violência totalitária. Rio de Janeiro: Zahar, 1981.

MENDES, Geisa do Socorro Cavalcanti Vaz. Avaliação institucional: estudo da implementação de uma política para a escola fundamental do município de Campinas/SP. 2011 . 332f. Tese (Doutorado em Educação) - Programa de Pós-Graduação em Educação, Universidade Estadual de Campinas, Campinas, 2011.

ORTEGA-RUIZ, Rosário; DEL REY, Rosário. Estratégias educativas para a prevenção da violência. Tradução Joaquim Ozório. Brasília: Unesco/UCB, 2002.

PARSONS, Talcott. El sistema social. Madrid: Alianza Editorial, 1988.

POSSATO, Beatris Cristina. O "professor mediador escolar e comunitário": uma mirada a partir do cotidiano escolar. 2014. 195f. Tese (Doutorado em Educação) - Programa de Pós-Graduação em Educação, Universidade Estadual de Campinas, Campinas, 2014.

POSSATO, Beatris Cristina; SCOTUZZI, Claudia Aparecida.Sistema de proteção escolar: proteger quem de que? In: SEMINÁRIO DE EDUCAÇÃO BRASILEIRA, 2; 2009, Campinas. Anais...Campinas: Universidade Estadual de Campinas, 2009.

ROYER, Égide. Condutas agressivas na escola: pesquisas, práticas exemplares e formação de professores. In: Desafios e alternativas: violência nas escolas. Brasília: UNESCO; UNDP, 2003. 
SÃO PAULO. Diretoria de Ensino de Limeira. Planejamento escolar 2010. Sistema de proteção escolar. 20 10. Disponívelem: http://www. delimeira.com.br/DE_novo/Anexos/Anexo\%20 III\%20Planejamento\%20do\%20Sistema\%20de\%20Prote\%C3\%A7\%C3\%A30\%20Escolar. pdf. Acesso em: 12 jan. 2011.

Secretaria da Educação do Estado de São Paulo. Manual de proteção escolar e promoção da cidadania. São Paulo: Fundação para o Desenvolvimento da Educação, 2009. - Secretaria da Educação do Estado de São Paulo. Normas gerais de conduta escolar. São Paulo: FDE, 2009a.

Secretaria da Educação do Estado de São Paulo. Ocorrência escolar. Disponível em: hitp://www.fde.sp.gov.br/PagesPublic/InternaRoe.aspx? contextmenu=roe. Acesso em: 25 abr. 2012.

. Resolução SE n. 19, de 12 de fevereiro de 20 10. Diário Oficial da União, Imprensa Oficial, Poder Executivo, São Paulo, 13 fev. 2010. Secção I, p. 29.

SOUZA, Silvana Aparecida de. Gestão escolar compartilhada: democracia ou descompromisso? São Paulo: Xamã, 2001.

SUPERVISOR. Entrevista. São Paulo (São Paulo), 16 maio 2012.

VON BERTALANFFY, Ludwing. Teoria geral dos sistemas. 2. ed. Petrópolis: Vozes, 1975.

ZALUAR, Alba; LEAL, Maria Cristina. Violência Extra e Intramuros. Revista Brasileira de Ciências Sociais, São Paulo, v. 16, n. 45,p. 145-163, fev. 2001.

Profa. Dra. Beatris Cristina Possato Universidade Estadual de Campinas | Unicamp Faculdade de Educação

Pesquisadora do Laboratório de Estudos em Políticas Públicas | LEPP | Unesp Bolsisła do Projeto Fundação para o Desenvolvimento da Unesp | FUNDUNESP Grupo de pesquisa Violar E-mail | biapossato@hotmail.com

Recebido 18 maio 2015 Aceito 16 out. 2015 